\title{
MOBILIZAÇÕES HOMOSSEXUAIS E ESTADO NO BRASIL: SÃO PAULO (1978-2004)*
}

\section{Gustavo Gomes da Costa Santos}

\section{Introdução}

Nos últimos anos, o movimento pelos direitos dos homossexuais tem ganhado grande visibilidade e importância no cenário político brasileiro, principalmente em virtude das diversas "Paradas do Orgulho GLBT", ${ }^{1}$ que têm chamado a atenção de todas as instâncias da sociedade. O objetivo deste texto é entender a relação do movimento homossexual com o Estado, ou seja, verificar como ela se dá e de que forma facilita ou dificulta a mobilização em torno da homossexualidade e

* O presente texto é fruto de resultados iniciais da pesquisa para a dissertação de mestrado em Ciência Política na Unicamp, intitulada Estado, projetos políticos e trajetórias individuais: um estudo com as lideranças homossexuais na cidade de São Paulo.

Artigo recebido em març/2005

Aprovado em marco/2006 a obtenção de direitos para a população homossexual.

Para isso, foram utilizadas diversas fontes de informação. Entrevistas semidiretivas, ${ }^{2}$ realizadas com militantes "históricos" do movimento homossexual e com militantes presentes no processo de rearticulação do movimento, em meados da década de 1990; material jornalístico pesquisado nas bases eletrônicas de dados da Folha de S. Paulo e do site MixBrasil direcionado à comunidade homossexual; participação em fóruns e eventos organizados pelo movimento homossexual; e, ainda, conversas informais com militantes, que também auxiliaram na delimitação e comprovação das hipóteses.

Busco reconsiderar o impacto que a epidemia de Aids $^{3}$ teve no movimento homossexual. O que ficou conhecido como a "peste gay" aumentou certamente o estigma relacionado à homossexualidade, acelerando o processo, então em curso, de desmobilização da militância a favor dos direi- 
tos homossexuais. Em contrapartida, a Aids tornou público o debate sobre a sexualidade, em parte devido à morte de figuras importantes da cultura brasileira, vítimas do HIV. Com efeito, essa epidemia trouxe uma maior visibilidade da homossexualidade no cenário nacional, abrindo espaço, em um primeiro momento, para o contato entre militantes homossexuais e órgãos estatais, o que gerou uma resposta relativamente prematura à doença por parte do Estado. Em um segundo momento, os recursos e financiamentos fornecidos pelo Ministério da Saúde a grupos homossexuais para a prevenção da doença na comunidade homossexual possibilitaram a reestruturação do movimento homossexual em todo o país.

Com base no conceito de estrutura de oportunidades políticas, tal como desenvolvido por Sidney Tarrow (2004), analisar-se-á também o surgimento do movimento homossexual em São Paulo e seus desdobramentos recentes. O processo de abertura política propiciou um clima favorável à difusão da ação coletiva de diversos movimentos sociais e teve impacto no surgimento do movimento homossexual. No ano de 2000, a eleição de Marta Suplicy para a prefeitura de São Paulo teve repercussão na conquista de novos espaços de interlocução entre o Estado e a comunidade homossexual.

Para desenvolver essa argumentação, proponho, em primeiro lugar, uma discussão da literatura brasileira sobre movimentos sociais, a fim de elucidar as principais mudanças ocorridas no campo de ação dos movimentos nas décadas de 1970, 1980 e 1990, juntamente com a exposição dos principais referenciais teóricos da análise. Em seguida, será feito um breve relato da trajetória do movimento homossexual na cidade de São Paulo. Por fim, serão analisados o impacto da epidemia de Aids, as inovações ocorridas nas mobilizações de homossexuais e a relação deste movimento com o Estado (principalmente na conjuntura do mandato de Marta Suplicy).

\section{Movimentos sociais: origem e transformações}

Durante o processo de redemocratização, as ciências sociais brasileiras deram grande ênfase à problemática dos movimentos sociais. Com a abertura política, diversos grupos puderam se organizar no sentido de reivindicar seus direitos de cidadania.

Os movimentos sociais, apesar de suas diferenças - desde aqueles que buscavam uma melhoria nas condições de vida até os que almejavam alterações no estilo de vida, tinham em comum o fato de se articularem em torno de reivindicações coletivas, definidas como "carências comuns" (Durham, 1984), e de apresentarem um potencial sociocultural transformador (Evers, 1984). Distantes dos meios burocráticos de participação, os movimentos eram caracterizados pelo baixo número de participantes e por adotarem formas coletivas de tomada de decisão, criando, assim, novas formas de individualidade, baseadas na autodeterminação e na emancipação (Durham, 1984; Evers, 1984). Mais ainda, os movimentos sociais promoveram a revalorização de práticas sociais do cotidiano popular, o que permitiu a elaboração de identidades coletivas com vistas a defender interesses e expressar vontades de sujeitos coletivos portadores de um projeto de transformação social (Sader, 1988).

$\mathrm{Na}$ sua maioria, as análises produzidas nos anos de 1970 e início da década seguinte enfatizaram o caráter transformador e emancipatório dos movimentos sociais. Tal ênfase, de um lado, e a crescente desmobilização e incapacidade de se colocar em prática o projeto político transformador, de outro, motivaram ou podem explicar, talvez, o grande "desalento" de boa parte da literatura brasileira sobre o tema no decorrer da década de 1980. Falava-se em "refluxo" ou, em alguns momentos, em "cooptação" dos sujeitos atuantes nesses movimentos. Entretanto, ao contrário do que anunciava a literatura, os movimentos sociais permaneceram atuantes e se tornaram atores importantes na sociedade civil (Lavalle et al., 2004). Creio que os estudos que alardeavam a "morte dos movimentos sociais" (Ottman, 1995) não analisaram de modo mais atento as transformações do contexto político e aquelas vivenciadas nos próprios movimentos sociais.

Uma das principais mudanças ocorridas foi o novo papel desempenhado pelo Estado. Considerado o grande "inimigo comum", o Estado passou a ser um importante interlocutor e, muitas vezes, aliado na consecução das reivindicações 
de diversos movimentos (Cardoso, 2004; Gohn, 2002). É importante salientar que o contato entre movimentos sociais e Estado já existia durante o regime militar (Cardoso, 1983), mas o processo de redemocratização e a eleição de governos comprometidos com o projeto de participação da sociedade civil abriram espaço para uma atuação conjunta de co-gestão e proposição de políticas públicas (Teixeira, 2003). Durante o processo constituinte também assistiu-se a uma ampla participação dos movimentos nos espaços políticos institucionais. Por meio dos "lobbies populares" (Idem), os movimentos atuaram de forma significativa na definição dos termos da Constituição de 1988. Conhecida como "constituição cidadã" (Dagnino, 2003), a Carta Magna garantiu, mesmo que apenas no plano legal-formal, antigas demandas dos movimentos sociais - amplos direitos sociais e a instituição de mecanismos de participação popular, como emendas populares, referendos e conselhos gestores de políticas públicas, entre outras (Carvalho, 1998; Teixeira, 2003).

Nos anos de 1990, o Estado brasileiro enfrentou outra importante mudança. Seguindo uma tendência latino-americana de resposta à crise fiscal dos Estados nacionais, baseada no que ficou conhecido como "Consenso de Washington" (Dagnino, 2003), o governo brasileiro iniciou um amplo programa de reforma do Estado, que, entre diversas ações, destacam-se as privatizações de empresas estatais, a derrubada de monopólios da prestação de serviços públicos (energia, telefonia) e a delegação, às organizações da sociedade civil, de funções de prestação de serviços sociais, antes sob a responsabilidade estatal (Teixeira, 2003). No bojo dessa redefinição da relação entre Estado e sociedade, as ONGs passaram a ter um papel mais ativo no campo de ação dos movimentos sociais (Doimo, 1995, Gohn, 2002; Teixeira, 2003). Podese dizer que elas "saíram da sombra" ao deixar de lado um trabalho de viés mais pedagógico com as lideranças populares para atuarem de forma efetiva nas ações coletivas (Gohn, 2002). Vale lembrar, contudo, que essas organizações também passaram a disputar espaço com grupos de movimentos sociais, uma vez que são mais preparadas do ponto de vista técnico (maior escolaridade de seu pessoal, maior infra-estrutura). Em conseqüência, muitos grupos ligados a movimentos sociais tor- naram-se ONGs, a fim de obter financiamentos e manter uma estrutura de mobilização mais ou menos estável, ao contrário dos antigos grupos, mais informalmente organizados (Teixeira, 2003). Embora as "parcerias" possibilitem a inserção de várias ONGs nos movimentos sociais, criou-se, segundo Gohn, uma "camada de dirigentes que cada vez mais se distanciam das bases dos movimentos" (2002, p. 286). Mais ainda, esses grupos tornam-se cada vez mais meros prestadores de serviços públicos, antes de responsabilidade estatal, e acabam por ter menos tempo para ações mais propositivas e de mobilização social (Teixeira, 2003).

Todo esse processo tem sido permeado por conflitos (Cardoso, 2004). De fato, não podemos deixar de levar em conta que os movimentos sociais, assim como o Estado, não são atores homogêneos, ao contrário, possuem diversas "faces", muitas vezes opostas entre si. Ao reconhecê-los como conflitos de ação direta, A. Doimo (1995) demonstrou que os movimentos sociais constituem campos éticos-políticos que oscilam entre um caráter expressivo-disruptivo, contestador da ordem estabelecida, e um caráter integrativo-corporativo, que busca a garantia de direitos e a integração dos grupo no interior sociedade. Nas palavras da autora:

[...] tais conflitos [de ação direta] apresentam um caráter altamente cambiante, podendo tanto adquirir um perfil pendular entre a defesa do estatismo e a reivindicação das vantagens do mercado, quanto oscilar entre condutas expressivo-disruptivas de negação do Estado e atitudes integrativo-corporativas de afirmação de sua face provedora (Idem, pp.52-53).

Uma das vertentes teóricas que trabalhou com a relação entre movimentos sociais e instituições políticas foi a teoria de Mobilização Política. Para o propósito deste trabalho, será utilizada a formulação dessa teoria tal como desenvolvida por Sidney Tarrow (2004). Para ele, entender o surgimento e a dinâmica dos movimentos sociais pressupõe a análise do conceito de estrutura de oportunidades políticas. ${ }^{4}$ Entendida como "[...] dimensiones consistentes - aunque no necesariamente formales, permanentes o nacionales - del entorno político que fomentan la acción colectiva entre la gente 
[...]" (Idem, p. 45), a estrutura de oportunidades políticas pode facilitar ou dificultar a ação dos movimentos sociais. Em contextos de oportunidades políticas favoráveis, a ação dos "desafiadores" expande as oportunidades para ou-tros grupos se mobilizarem, gerando "ciclos de pro- testo". Nesses ciclos, ocorre a difusão da ação coletiva de setores mais mobilizados para os menos mobilizados, marcados por um ritmo acelerado de inovação nas formas de confrontação, nos marcos de referências da ação coletiva, e pela combinação de participação organizada e não organizada (Idem, pp.202-203).

Além dos contextos de grande mobilização, os movimentos sociais dispõem de outras bases para empreender a ação coletiva, como, por exemplo, os repertórios de ação coletiva. Definidos como a "[...] totalidad de los medios de que dispone (un grupo) para perseguir intereses compartidos" (Idem, p. 59), os repertórios dependem das oportunidades e da organização do movimento. Eles se transformam com o passar do tempo, mas em ritmo "glacial", e são herdados pelos movimentos. Mesmo assim, Tarrow afirma que "[...] existe espacio para la innovación y la espontaneidad" e que "tales innovaciones [...] pueden limitarse a animar una forma convencional de acción colectiva [...] pero, con el tiempo, las innovaciones pueden cristalizar en formas completamente nuevas" (Idem, p. 149).

Outra base para a ação dos movimentos é a criação de marcos de referência (frames). Enquanto esquemas interpretativos que simplificam e condensam a realidade, ao pontuar de forma seletiva situações, experiências e acontecimentos, os marcos constituem a dimensão simbólica da ação coletiva. Ao auxiliar os movimentos na identificação de injustiças, atribuindo responsabilidades e propondo soluções, eles permitem que novas idéias e símbolos sejam incorporados à matriz cultural existente (Idem, pp. 160-162).

Tarrow pontua também a importância das redes sociais existentes entre membros do movimento. Elas facilitam, de acordo com o autor, a comunicação e a troca de informações e experiências de mobilização entre os indivíduos, bem como possibilitam a manutenção do contato dos membros de um determinado movimento em períodos de repressão ou desmobilização.

É na conjunção de fatores externos e inter- nos que podemos explicar o "poder" dos movimentos sociais Ao comparar o movimento estudantil francês da década de 1960 ao movimento feminista norte-americano, Tarrow demonstra como a habilidade das feministas em conjugar as diversas dimensões da ação coletiva foi decisiva para seu relativo "sucesso". Apesar de uma organização a princípio débil e do acesso restrito ao sistema político, as feministas conseguiram articular diversas formas de ação (direta ou lobista) e de organização (grupos informais e de interesse), tornando pública a questão de gênero e garantindo programas de ação afirmativa e leis favoráveis à questão feminina. Com base nesse exemplo, o autor mostra a importância da interação dos movimentos sociais com as instituições políticas, mas afirma, em contrapartida, que isso pode ser uma "faca de dois gumes", uma vez que

[...] los movimientos sociales demasiados marginalizados por las instituciones corren el riesgo del aislamiento y el sectarismo; pero los que colaboran excesivamente com ellas y asumen rutinas institucionales pueden verse imbuidos de su lógica y sus valores (Idem, p. 289).

\section{Trajetória do movimento homossexual na cidade de São Paulo (1978-2004)}

\section{A emergência do movimento homossexual}

A fundação do grupo Somos, em 1978, é considerada o marco do início da luta política dos homossexuais em São Paulo e no Brasil (MacRae, 1990; Green, 2000; Trevisan, 2000). Em um momento de extrema efervescência política, oriunda do processo de abertura do regime militar, milhares de movimentos sociais emergiram em torno de diversas reivindicações coletivas. Juntamente com a mobilização das mulheres contra o machismo e o sexismo, os homossexuais buscaram, pela primeira vez no país, politizar a homossexualidade, a fim de romper os limites do gueto e reivindicar direitos iguais.

Nesse contexto de contestação ao status quo surge o jornal Lampião da Esquina, um dos expo- 
entes da chamada imprensa "nanica". Ao criticar o autoritarismo presente tanto nas instituições políticas como na própria sociedade, o Lampião levantou a questão da homossexualidade em seus aspectos político, existencial e cultural (MacRae, 1992). Esse jornal converteu-se no grande divulgador das idéias propostas pelo Somos e outros grupos do incipiente movimento homossexual, embora esta relação, entre o jornal e os grupos de militância, não tenha ocorrido sem conflitos (MacRae, 1990).

Era consenso no movimento homossexual a rejeição a qualquer forma de autoritarismo, fosse este oriundo da repressão do regime militar, das hostes da esquerda, fosse o ocorrido na relação entre homem e mulher ou mesmo entre o casal homossexual. Como outros movimentos sociais da época, o movimento homossexual dava grande ênfase à sua autonomia em relação a partidos políticos. Também propunha um modelo igualitário de identidade sexual, rejeitando modelos hierárquicos de relações sexuais/afetivas presentes na cultura brasileira (Fry, 1982) e reivindicando uma identidade homossexual na qual se identificariam todos aqueles que eram vítimas da discriminação e do preconceito independentemente das diferenças existentes dentro da comunidade homossexual (MacRae, 1990).

Devido ao discurso fortemente antiautoritário dos movimentos sociais do período, o Estado era considerado o principal inimigo na luta pela democracia, e o movimento homossexual teve, nesse sentido, uma participação efetiva. Visto que os canais convencionais de interlocução entre Estado e sociedade encontravam-se fechados, a ação do grupo Somos esteve muito voltada para o trabalho de conscientização de seus membros e de setores progressistas da sociedade. O grupo participou de vários eventos em universidades e em manifestações de contorno mais propriamente "político", como o $1^{\circ}$ de Maio de 1980, em São Bernardo do Campo, o que comprova o esforço do grupo em divulgar a causa homossexual. Porém, a mais importante mobilização do Somos foi a campanha contra a violência policial (Idem, 1990). A ação conjunta das polícias civil e militar desencadeou uma caça brutal aos freqüentadores da noite no centro de São Paulo, sobretudo prostitutas, travestis e homossexuais.
Dado o clima de relativa liberalização com a proximidade das eleições de 1982, a ação do delegado José Wilson Richetti gerou uma ampla mobilização do Somos e de diversos grupos, inclusive aqueles oriundos dos movimentos feminista $\mathrm{e}$ negro (Idem). Apoiavam a causa parlamentares da oposição e de algumas celebridades do mundo artístico. Dessas articulações foi organizado um ato público em frente ao Teatro Municipal, em 13 de junho de 1980 (Trevisan, 1986; MacRae, 1990). As estimativas calcularam entre quinhentos a mil participantes, que caminharam pelo centro da cidade sem encontrar repressão policial. Além disso, o Conselho Parlamentar de Direitos Huma-nos convocou o delegado Richetti para prestar esclarecimentos sobre a ação na Assembléia Legislativa. Participaram integrantes de vários grupos homossexuais e feministas. A presença de parlamentares do PDS $^{5}$ e o despreparo dos parlamentares da oposição, com receio de ofender as convicções moralistas de seu eleitorado, impossibilitaram uma ação mais enérgica contra o delegado Richetti. Mesmo assim, a ação conjunta foi suspensa, criando-se uma sensação de vitória mo-mentânea para os grupos homossexuais (MacRae, 1990). No momento da campanha contra a violência policial, o Somos encontrava-se em processo de cisão interna (MacRae, 1990; Trevisan, 2000). E é neste momento que surgem as primeiras notícias de casos de Aids.

\section{O movimento homossexual e a Aids}

Embora o primeiro caso de Aids tenha sido diagnosticado em 1981 nos Estados Unidos, só em 1983, com a morte do estilista Marco Vinicius Resende, o Marquito, a Aids tornou-se uma realidade no Brasil. ${ }^{6}$ Amplamente divulgada na mídia como a "peste gay" ou "câncer gay", a Aids reforçou o pânico geral contra a homossexualidade. Entre os homossexuais, a presença da doença gerou muitas dúvidas devido à falta de informação. ${ }^{7}$ Com as primeiras mortes, muitos militantes homossexuais ficaram assustados, como relata uma ex-militante do grupo Somos: "[...] eu lembro que encontrei um ex-militante do Somos que tinha virado evangélico [...] ele tinha virado evangélico e queria de qualquer forma se curar da homossexualidade, ele tava apavorado". ${ }^{8}$ 
Em contrapartida, outra parte da militância passou a se mobilizar no sentido de buscar soluções para a doença. Integrantes do grupo Somos, do grupo Outra Coisa (dissidente do Somos) e militantes homossexuais em geral procuraram o serviço de saúde com o intuito de obter ajuda estatal no combate à epidemia. ${ }^{9}$ Dessa iniciativa começou a ser organizado o I Programa de Combate à Aids no país (Silva, 1986; Parker, 1994; Terto Jr., 1996; Texeira, 1997; Galvão, 2000). O fato de haver na época um governo (Franco Montoro [1983-1987]) interessado na participação da sociedade civil, aliado a uma equipe de sanitaristas progressistas, explica a resposta relativamente prematura à epidemia no Brasil (Teixeira, 1997; Galvão, 2000).

Devido ao avanço da epidemia e ao processo de desmobilização dos grupos homossexuais em curso, o caráter da militância homossexual sofreu grande mudança. A emergência da doença inaugurou uma nova fase do movimento (Facchini, 2002). As discussões acerca da questão homossexual foram deixadas de lado em virtude da "urgência" em se produzir uma resposta à epidemia. ${ }^{10} \mathrm{~A}$ fundação do Gapa, em 1985, pode ser considerada um marco dessa mudança. Em uma das entrevistas foi relatado que parte significativa dos membros fundadores desse grupo era de homossexuais e que muitos deles já haviam militado antes em outros grupos, como o Somos. ${ }^{11}$ Inicialmente, as ações desses grupos visavam a um trabalho assistencialista - doação de cestasbásicas, roupas e remédios e organização de eventos para angariar fundos para o socorro às vítimas da doença. ${ }^{12}$ A participação mais efetiva do Estado em relação aos grupos mais prejudicados pela Aids possibilitou a criação de "referenciais não-discriminatórios e de defesa dos direitos dos afetados" nos serviços de saúde (Galvão, 2000, p. 121) e influenciou outras respostas governamentais por todo o país.

Embora basicamente envolvidos com atividades voltadas ao combate à Aids, vários grupos mantiveram atividades mais relacionadas à discussão em torno da homossexualidade. O principal deles foi o grupo Gay da Bahia (GGB), que continuou a se empenhar em campanhas que não se restringissem apenas ao combate à Aids (MacRae, 1990), como, por exemplo, a campanha, em colaboração com o grupo Somos, pela mudança do código de classificação de doenças do Inamps em 1982, que descrevia a homossexualidade como "desvio ou transtorno sexual". Outra importante ação do movimento homossexual foi a campanha pela mudança do Código de Ética dos Jornalistas, ${ }^{13}$ organizada pelos grupos Triângulo Rosa (RJ), GGB (BA) e Lambda (SP), incluindo o termo "orientação sexual" nas proibições do Artigo 10, ${ }^{14}$ a fim de minimizar "os preconceitos constantemente reafirmados pela imprensa" (Silva, 1993, p. 123).

O Grupo Lambda foi um dos poucos grupos gays a manter atividades em São Paulo durante a década de $1980 . .^{15} \mathrm{Um}$ dos entrevistados relatou que nas reuniões do grupo era possível perceber o caráter informal e esporádico de suas atividades: "[...] eram grupos pequenos, nunca uma reunião onde havia mais de três militantes [...] quando eu ia à casa dele [Ubiratan da Costa e Silva], o máximo que eu encontrava eram uma ou duas pessoas". ${ }^{16}$

Embora fortemente vinculado ao combate à Aids, seu principal expoente, Ubiratan da Costa e Silva, manteve contato com grupos gays de outras partes do país, engajando-se em mobilizações no âmbito local - como o pronunciamento, juntamente com o Gapa, contrário à ação do prefeito Jânio Quadros, que proibiu o ingresso de homossexuais na Escola Municipal de Bailado em $1987^{17}$ - e na esfera federal - participação em debates do movimento homossexual e suporte ao grupo Triângulo Rosa na Assembléia Nacional Constituinte (Silva, 1993). Trazer a questão homossexual para as discussões da Constituição foi um fato de grande relevância, pois possibilitou o contato com parlamentares que se sensibilizaram com a causa e, mais tarde, tornaram-se importantes interlocutores do movimento homossexual no Congresso Nacional. Nas entrevistas não foram obtidas informações precisas a respeito do fim das atividades do Lambda. Mas Galvão (2000) relata a participação do grupo na organização do III Encontro da Rede Brasileira de Solidariedade (ONG/Aids), ocorrido em Santos, em 1990, e presume-se que as atividades do grupo permaneceram pelo menos até a morte de Ubiratan da Costa e Silva, em 1993, vítima da Aids.

Em relação aos grupos lésbicos, o Galf (Grupo de Ação Lésbica-Feminista), oriundo do 
"racha" no interior do grupo Somos, manteve atividades durante toda a década de 1980, principalmente no gueto lésbico e no movimento feminista $^{18}$ (Pontes, 1986; MacRae, 1990). Segundo Silva (1993), o Galf participou de discussões que resultaram na utilização nos debates da Constituinte do termo "orientação sexual", em vez de "preferência sexual" ou de "opção sexual" ${ }^{19}$ Porém, foi apenas no início da década de 1990 que os contatos entre os grupos gays e lésbicos se tornaram mais intensos.

\section{Década de 1990 e a rearticulação do movimento homossexual}

Um dos entrevistados ${ }^{20}$ aponta O VII Encontro Brasileiro de Lésbicas e Homossexuais, realizado em 1993 em Cajamar (SP), como fundamental para a rearticulação do movimento tanto em São Paulo como no Brasil. Como relata Facchini (2002), o encontro teve aumento significativo no número de participantes, com o predomínio dos grupos lésbicos (a maioria de São Paulo), e contou, também, com a presença de novos grupos gays e mistos da cidade, ${ }^{21}$ além de diversas ONG-Aids (ONGs especializadas em trabalho de prevenção à doença). Tal diversidade de atores refletiu-se nas discussões que ocorreram desde a paridade entre gays e lésbicas nas instâncias do movimento, a participação do movimento homossexual no consórcio de vacinas anti-HIV e no I Congresso de Movimentos Populares, até a possível criação de uma entidade para articular o movimento em âmbito nacional (Facchini, 2002).

Outro importante evento para a rearticulação do movimento em São Paulo foi a XVII Conferência da ILGA (International Lesbian and Gay Association) no Rio de Janeiro, em 1995, que contou, de acordo com o relato de um dos entrevistados, ${ }^{22}$ com a presença de vários militantes homossexuais de São Paulo. A sexóloga e então deputada Marta Suplicy, presidente de honra da Conferência, apresentou a primeira versão do projeto de lei de união civil entre pessoas do mesmo sexo, ${ }^{23}$ tema que mobilizou boa parte das discussões do encontro e que possibilitou, posteriormente à conferência, a reunião de Marta Suplicy com militantes de São Paulo. ${ }^{24}$ Em janeiro do mesmo ano, realizaram-se o I Encontro Brasileiro de Gays e Lésbicas que Trabalham com Aids e o VIII Encontro Brasileiro de Gays e Lésbicas, ${ }^{25}$ os quais, entre outras resoluções, aprovaram a fundação, a despeito da oposição de vários grupos presentes, da ABGLT (Associação Brasileira de Gays, Lésbicas e Travestis) (Green, 2000; Facchini, 2002).

Em 1996, foi lançada a primeira candidatura gay à Câmara Municipal de São Paulo ${ }^{26}$ pelo Partido dos Trabalhadores. Mesmo com o apoio da deputada Marta Suplicy, a candidatura não obteve sucesso. Em 1997, o IX Encontro Brasileiro de Gays, Lésbicas e Travestis e o II Encontro Brasileiro de Gays, Lésbicas e Travestis que Trabalham com Aids (EBGLT-Aids) ocorreram mais uma vez em São Paulo, com a participação de 52 grupos tanto da militância GLT (Gays, Lésbicas e Travestis) como de ONG-Aids e simpatizantes. Havia muito conflito entre seus organizadores, sendo que vários grupos foram excluídos da comissão de organização. ${ }^{27}$ Apesar disso, foi neste ano que os grupos de São Paulo organizaram a Parada do Orgulho GLT, que se tornou símbolo do movimento homossexual no Brasil. Mesmo depois de uma primeira tentativa frustrada em 1996, em 28 de junho de 1997, aproximadamente duas mil pessoas seguiram pela Avenida Paulista ${ }^{28}$ com o intuito de atrair a atenção da sociedade e dar visibilidade pública às reivindicações dos homossexuais. A Parada do Orgulho GLBT $^{29}$ passou a acontecer todos os anos, tornando-se parte integrante do calendário oficial da cidade. Ao reunir aproximadamente um milhão e meio de pessoas, ${ }^{30}$ esse evento passou a ser uma das principais formas de o movimento homossexual afirmar sua existência como sujeito político.

Em 2000, o assassinato do adestrador de cães Edson Néris da Silva, na Praça da República, por um grupo de Skinheads conhecido como "Carecas do ABC", simplesmente por estar andando de mãos dadas com um amigo, chocou a opinião pública e a militância homossexual. Os grupos reagiram com várias medidas, entre elas uma vigília contra a violência aos homossexuais e diversas ações junto a parlamentares e autoridades do Judiciário. ${ }^{31}$ No mesmo ano, foi eleita prefeita a ex-deputada Marta Suplicy. ${ }^{32}$

Além da novidade representada pela Parada do Orgulho, o movimento homossexual utilizou 
outra forma inovadora de mobilização que ficou conhecida como "beijaço". Nesse tipo de ação, os militantes beijam-se em espaços públicos ou privados onde ocorreram episódios de discriminação contra homossexuais. Em São Paulo, ocorreram duas ações desse tipo. A primeira em um bar, acusado de expulsar um casal de lésbicas por se beijarem, sob a justificativa de que a proprietária não queria que o bar fosse identificado como "bar gay". ${ }^{33}$ A de maior repercussão, entretanto, foi realizada no Shopping Frei Caneca e contou com aproximadamente 3 mil pessoas. ${ }^{34}$

Além disso, o movimento homossexual em São Paulo tem tido um intenso trabalho com parlamentares - a formação de uma "Frente Parlamentar pela Livre Expressão Sexual" na Assembléia Legislativa; ${ }^{35}$ as vitórias obtidas no campo legal, como a aprovação de uma lei estadual antidiscriminação ${ }^{36}$ por orientação sexual; a criação de uma defensoria homossexual, ${ }^{37}$ vinculada ao Ministério da Justiça e primeira do gênero no Brasil, e a aprovação da possibilidade de recebimento de pensão por parte de parceiros homossexuais no Iprem (Instituto de Previdência Municipal de São Paulo)..$^{38}$

Ao combinar diversas formas de ação, o movimento homossexual tem conseguido dar visibilidade à sua causa. Embora tenha sofrido grande impacto com a epidemia de Aids, nos anos de 1980 o movimento conseguiu manter diversas ações de defesa da população homossexual. Na década seguinte, com a diminuição do estigma que relaciona a Aids à homossexualidade e o auxílio dos recursos oriundos de financiamentos para a prevenção da doença, os grupos homossexuais conseguiram se rearticular, promovendo diversos encontros nacionais e internacionais e inovando nas formas de mobilização, a exemplo das "Paradas" e dos "beijaços". Essas ações tiveram como resultado a maior interlocução com os poderes públicos e a garantia, mesmo que de forma restrita, de uma legislação favorável à comunidade homossexual, como a lei 10.948/2001, que pune "toda manifestação atentatória ou discriminatória praticada contra cidadão homossexual, bissexual ou transgênero".

\section{AIDS, estrutura de oportunidades politicas e o movimento homossexual}

\section{O impacto da Aids}

A trajetória do movimento homossexual foi caracterizada por vários desafios, mas sem dúvida o maior deles foi a Aids. Em uma atmosfera de abertura política e relativa liberalização dos costumes, a Aids surge trazendo consigo velhos preconceitos e estigmas sociais. Tachada pela imprensa de "peste gay" ou "câncer gay", a Aids representava, para setores conservadores, a resposta ao "desbunde" dos anos de 1970 (Galvão, 2000) e o fim dos ideais libertários da contracultura, amplamente divulgados pela máxima "Sexo, Drogas e Rock 'n Roll" (Messeder Pereira, 2004).

A morte de milhares de pessoas, inclusive figuras ilustres, expôs à sociedade a questão da sexualidade. E, ao se falar em sexualidade, é necessário falar em todas as suas expressões, inclusive a homossexualidade. O debate público sobre esse tema causou impacto no movimento homossexual (Cerqueira e Mott, 2002). Como afirma Messeder Pereira:

Se, de um lado, ela [a Aids] veio reforçar antigos preconceitos que já pareciam ultrapassados [...], por outro, ela, pelo enorme drama social que evoca, coloca as sociedades e os Estados em confronto direito com a necessidade de implementar [...] políticas de prevenção, o que os obriga, [...] a lidar diretamente com os grupos gays organizados (2004, p. 59).

Não é o mero surgimento da doença que "força" os governos a lidarem com o problema. No caso brasileiro, a emergência da doença ocorreu em um contexto de oportunidades políticas favoráveis (Tarrow, 2004). A existência de uma militância homossexual (embora em processo de desmobilização), combinada com a eleição de Franco Montoro para o governo do Estado de São Paulo - governo comprometido com um projeto participativo (MacRae, 1997; Teixeira, 2003) -, explica a prematura resposta governamental à epidemia (Terto Jr. 1996; Teixeira, 1997; Galvão, 2000). Já no 
caso norte-americano, em que o movimento homossexual era bem organizado, pelo contrário, a administração republicana ignorou a existência do problema, e setores conservadores utilizaram a Aids como argumento contra a luta pelos direitos homossexuais (Vaid, 1995; Engel, 2001). Esta recusa do Estado em produzir respostas à doença teve como corolário o fortalecimento de novas formas de ativismo político, menos institucionalizados e mais voltados para formas de ação direta e contestatória da ordem (como, por exemplo, o movimento ACT UP) (Engel, 2001).

Outro ponto que merece destaque diz respeito à identificação dos homossexuais como "grupo de risco". Se a definição de "grupo de risco" aumentou o estigma e a exclusão desses grupos, ela também justificou a "importância de traçar estratégias específicas para essas populações, fazendo com que os seus integrantes se tornassem elementos importantes nas ações de prevenção [...]" (Galvão, 2000, p. 83). Vale lembrar, por outro lado, que os grupos de prevenção fizeram esforços para desvincular a Aids da comunidade homossexual, o que juntamente com o aumento do número de casos, na década de 1990, entre heterossexuais (principalmente mulheres) acabou por "auxiliar" nesse sentido.

A relevância do trabalho de grupos gays na prevenção da Aids explica o apoio financeiro dado a eles pelo Estado (principalmente via Programa Nacional de DST-Aids) e, em menor medida, pelas organizações de cooperação internacional (Idem). O trabalho conjunto entre o Estado e a sociedade civil tem sido apontado como um dos principais fatores do sucesso do Programa Nacional de DSTAids no combate à epidemia no Brasil e serve como exemplo de gestão bem-sucedida para outros países (Idem). Não foi por acaso que a campanha do então candidato governista à presidência, José Serra enfatizou sobremaneira suas realizações como ministro da Saúde (Gauri e Lieberman, 2004). Outro dado importante dessa "parceria" é o apoio dado pelo Programa Nacional para a realização de eventos regionais, nacionais e internacionais. Como estabelece o relatório do Ministério da Saúde:

A sustentação de projetos dessa natureza [apoio à realização de encontros] tem contribuído para o fortalecimento de diversos movimentos sociais, intensificando as ações de prevenção e assistência na mesma proporção em que permite a identificação de pontos de convergência que caracterizam o perfil de segmentos sociais a ser trabalhado (Ministério da Saúde, 1998, p. 62).

Ciclo de protesto, inovações nos repertórios de ação coletiva e o papel das redes sociais

No caso específico de São Paulo, a existência de uma estrutura de oportunidades políticas favorável (Tarrow, 2004) e a intensa mobilização social que se disseminou no país no final da década de 1970 foram decisivos para o movimento homossexual em seus primórdios. O processo de abertura política e a menor capacidade de repressão do Estado geraram um ciclo de protestos (Idem), no qual o movimento homossexual foi favorecido pela difusão de ação coletiva dos grupos pioneiros. Com efeito, houve, nesse período, uma grande interação entre diversos movimentos sociais, tornando o contato entre grupos extremamente frutífero para a luta contra o autoritarismo e pelo direito à diferença. Grupos de homossexuais passaram a ter contato direto com a causa feminista e dos negro (MacRae, 1990).

No que diz respeito aos repertórios de ação coletiva, o movimento homossexual inovou nas formas de mobilização no Brasil. Influenciado pelo exemplo das Gay Pride Parades norte-americanas, o movimento adotou esse tipo de ação para dar visibilidade à causa homossexual. Com a crescente participação da comunidade homossexual, assim como de heterossexuais, as Paradas conseguiram atrair a atenção dos meios de comunicação de massa, inserindo a questão dos direitos homossexuais na pauta de discussão política. Os "beijaços", inspirados nos Kiss-in norte-americanos, também aparecem como uma inovação da mobilização homossexual no Brasil. A crescente imagem que o mercado segmentado GLS ${ }^{39}$ passou a ter na mídia e a ênfase no poder de consumo dos homossexuais (a idéia do pink money ${ }^{40}$ ) contribuíram também para tais experimentações. Esse contexto de maior visibilidade do mercado GLS e de uma cultura gay (Facchini, 2002; Nussbaumer, 2001), somado à presença de aliados nas instituições políticas (Tarrow, 2004), repercutiu na sociedade civil, o que revela o aumento expressivo da participação nas Paradas nos últimos anos. 
Figura 1

Participação nas Paradas do Orgulho GLBT SP (1997-2004)

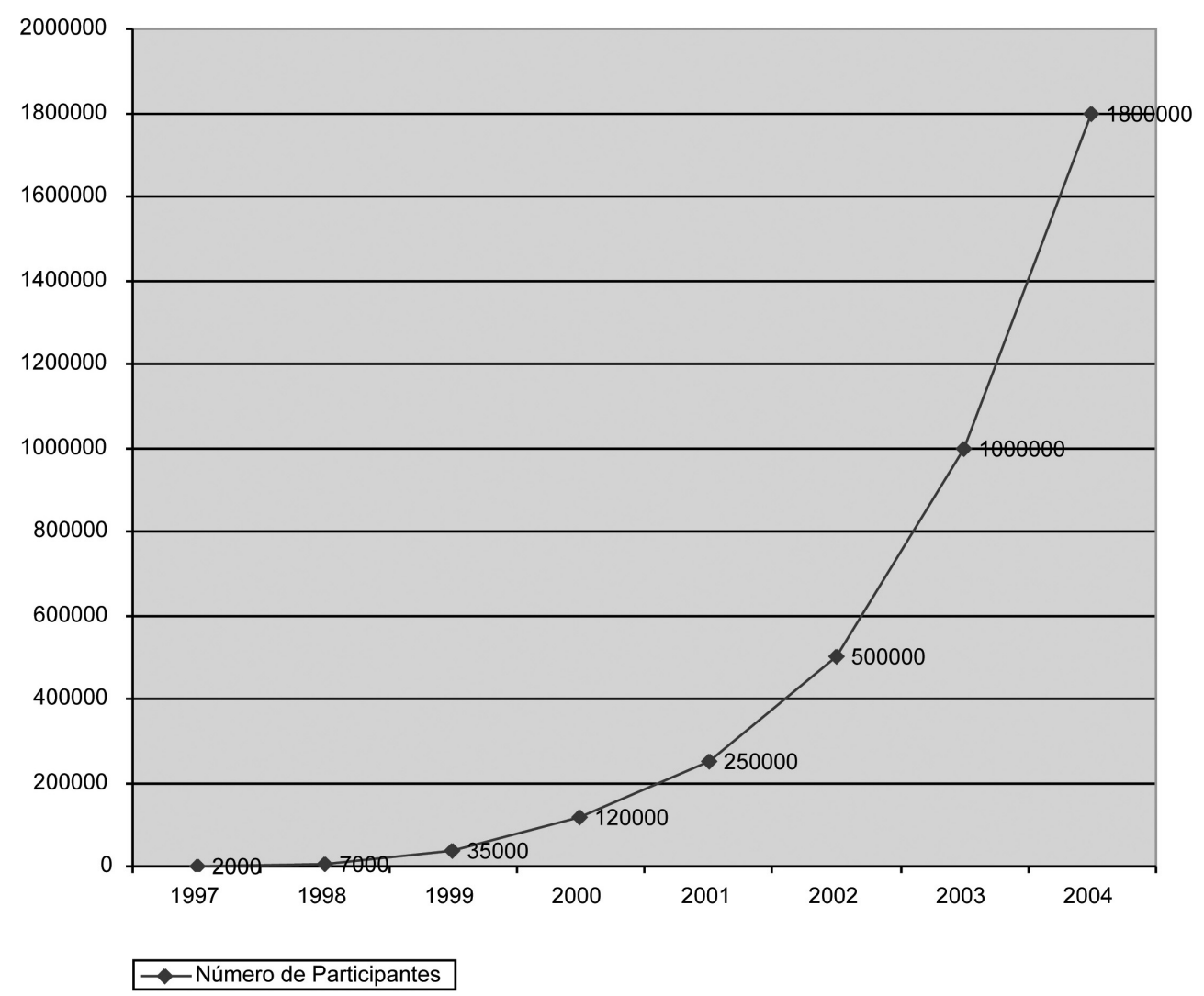

Fonte: Revista Oficial da Parada do Orgulbo GLBT de SP, $1^{\mathrm{a}}$ edição.

Concernente às redes sociais, elas tiveram grande importância na participação dos militantes homossexuais na organização do primeiro serviço de prevenção à Aids em São Paulo (Galvão, 2000), dado que o movimento se encontrava em processo de desmobilização, depois do "racha" ocorrido no grupo "Somos" (MacRae, 1990). A realização da Ilga, em 1995, teve impacto na transmissão de experiências de militância e de mobilização entre militantes brasileiros e estrangeiros. ${ }^{41}$ A realização dos Encontros Nacionais, apesar dos conflitos subjacentes, também possibilitou a construção de redes de amizade e de trocas de informação, agilizadas por mecanismos modernos de comunicação, como a internet. A tentativa de articulação das redes de militantes, no sentido de coordenar as ações do movimento homossexual em âmbito nacional, é um dos grandes desafios do movimento hoje.
Movimento homossexual e o Estado: limites e possibilidades

Como afirmado anteriormente, a presença de uma estrutura de oportunidades políticas favorável possibilitou os primeiros contatos da militância homossexual com órgãos estatais. À exceção da participação na Constituinte, esse contato permaneceu restrito, nos anos de 1980 e em parte da década seguinte, às instâncias estatais de saúde secretarias estaduais e municipais de saúde, Ministério da Saúde e, mais especificamente, o Programa Nacional de DST-Aids (PN DST-Aids). ${ }^{42}$ A crescente desvinculação dos homossexuais como "grupos de risco" e a manutenção dos recursos do PN DST-Aids ${ }^{43}$ possibilitaram a reestruturação do movimento homossexual em todo o país (Facchini, 2002). Inaugurou-se um novo momento na luta homossexual, caracterizado por uma rela- 
ção com o Estado mais efetiva - exemplo disso é a fundação da ABGLT e a apresentação, na Câmara dos Deputados, do projeto de reconhecimento de união entre pessoas do mesmo sexo.

Recentemente, a eleição da prefeita Marta Suplicy teve impacto nas mobilizações e no maior contato do movimento homossexual com o Estado, em São Paulo. Conhecida pelo seu trabalho em defesa dos direitos homossexuais, a prefeita implementou, no âmbito do poder municipal, diversas ações afirmativas para a comunidade GLBT: possibilidade de recebimento de pensão por parte de parceiros homossexuais no Iprem (Instituto de Previdência Municipal de São Paulo); ${ }^{44}$ apoio logístico para a realização das Paradas do Orgulho GLBT; capacitação de professores e funcionários da rede pública municipal para lidar com as diferenças (projeto "Educando para a diversidade"), ${ }^{45}$ realizado pelo Grupo Corsa, ${ }^{46}$ e a garantia de um representante do segmento GLBT no Orçamento Participativo, ${ }^{47}$ entre outras.

A relação da prefeita com o movimento e a comunidade homossexual, no entanto, foi permeada por conflitos. Um deles foi devido ao fechamento do "Autorama", espaço de convivência gay localizado ao lado do Parque Ibirapuera. A prefeitura interditou o local, sob a alegação de que o lugar estava sendo utilizado como ponto de prostituição e tráfico de drogas. ${ }^{48}$ Menos de um mês depois, o então presidente da Associação da Parada do Orgulho GLBT interveio e o espaço foi reaberto sob a condição de se criar um grupo de discussão sobre seu funcionamento, ${ }^{49}$ De onde partiu a proposta de tornar o espaço um "jardim gay". ${ }^{50}$ Embora apoiada por setores do movimento homossexual, ${ }^{51}$ a idéia foi criticada por vários militantes como sendo um "factóide" 52 e uma "ação para normatizar a vida sexual das pessoas". ${ }^{33}$ Ainda não se encontrou uma solução definitiva para o uso desse espaço.

Tal como Tarrow (2004), vários militantes pontuaram os "perigos" deste contato mais próximo com as instituições políticas. Segundo um dos entrevistados, a respeito da relação de "dependência" entre os grupos e os recursos do Programa Nacional de DST-Aids: "você vai ver que vários grupos foram criados para lutar contra a Aids, para poder pegar dinheiro do Ministério da Saúde. Grupos de direitos homossexuais, e que inseriam no seu programa a luta contra a Aids para poder ganhar dinheiro [...]" ${ }^{54}$ Além disso, o vínculo com o Estado limitaria a capacidade reivindicativa do movimento. Como afirma o relato de uma entrevistada:

A impressão que eu tenho é assim: o movimento social, no geral, virou, a boa parte da liderança virou funcionário do partido. [...] Porque eu acho assim, o fato do partido estar lá e ter uma abertura, isso não tira do movimento a responsabilidade de continuar lutando. A impressão que eu tenho é que é assim: ah, o PT é legal, 'tá' no poder, ahh, vamos sentar [...] e descansar, porque eles vão fazer tudo. [...] Quem tem que continuar fazendo é o movimento. [...] A minha participação, a minha colaboração, é como cidadã. É o caminho que eu acho legal. Agora, se não tá bom, eu é que tenho que fazer. Eu não vou esperar que eles, sentadinho lá no Governo, tendo que pensar no país inteiro, tendo que pensar numa cidade inteira, pense: "ahh, vamos buscar procurar um projeto perfeito para essa categoria". Não, o projeto perfeito quem tem que colocar somos nós e a gente tem que fazer inclusive a pressão $[\ldots . . .55$

\section{Considerações finais}

Ao longo desses 25 anos de história, o movimento homossexual enfrentou diversos desafios e passou por grandes transformações. De um movimento libertário e contracultural, passou a ter uma feição mais pragmática (ou, segundo Doimo (1995), integrativo-corporativa), o que se constata pela interação progressiva com atores importantes do status quo, como o Estado e o mercado.

O caráter mais pragmático da militância foi acompanhado da crescente visibilidade do movimento na mídia, da maior presença da temática homossexual em atividades artísticas (de peças de teatro a novelas) e da legitimidade, ainda incipiente, das reivindicações homossexuais perante a sociedade.

Embora o perigo de ser "cooptado" pela lógica estatal permaneça (de acordo com os comentários dos entrevistados), a interação dos grupos homossexuais com o Estado foi fundamental para a construção de uma política mais eficaz de combate à Aids (Galvão, 2000; Gauri e Lieberman, 
2004). Além disso, esse contato possibilitou a aprovação da lei estadual 10.948, além de levar a questão da diversidade sexual para outros âmbitos da ação estatal (a exemplo do programa "Educando para a diversidade").

Como se procurou demonstrar, a confluência de fatores externos ao movimento homossexual (como uma estrutura de oportunidades políticas favorável e o advento da Aids) com fatores internos (como a capacidade de mobilização e inovação nos repertórios de ação coletiva) demonstra o "poder" adquirido pelo movimento homossexual em inserir suas demandas na agenda pública e reivindicar seus direitos de cidadania. Apesar disso, o grande número de assassinatos de homossexuais, ${ }^{56}$ a exemplo do caso Edson Néris em São Paulo, e a ampla homofobia existente na população revelam à militância homossexual os desafios futuros na luta pela garantia de direitos humanos para a população homossexual.

\section{Notas}

1 GLBT - Gays, Lésbicas, Bissexuais e "Transgêneros". Após muita discussão no interior do movimento, optou-se, na década de 1990, pelo uso desta sigla, a fim de contemplar os diversos segmentos pertencentes ao que denominamos genericamente movimento homossexual. Para mais detalhe, ver Facchini (2002)

2 Os nomes dos entrevistados são fictícios.

3 Síndrome da Imunodeficiência Adquirida.

4 Para Tarrow, a estrutura de oportunidades políticas tem cinco dimensões principais: a) abertura do sistema político: cria maiores estímulos para participação; b) evidências de realinhamentos políticos dentro do sistema: gera incertezas entre os participantes do governo e encoraja os desafiantes a exercitar seu poder, induzindo as elites a buscar apoio fora do âmbito da política institucional; c) aparecimento de aliados fortes: é um importante incentivo, já que podem tanto garantir a nãorepressão do movimento, como possibilitar um canal de negociação nas instâncias governamentais; d) divisões das elites: diminuem os custos de mobilização, o que facilita a ação dos movimentos com poucos recursos; e) declínio na capacidade do Estado de reprimir dissensões: a maior probabilidade de não-repressão do movimento gera incentivos para a mobilização.
5 Partido Democrático Social, então partido governista.

Entrevista com Alexandre, 1/12/2004. Ex-militante do grupo Somos, ele esteve presente nas primeiras articulações do movimento homossexual em resposta à Aids, tendo participado do Gapa (Grupo de Apoio a Portadores de Aids) e de reuniões de outros grupos ligados ao movimento homossexual na década de 1990

6 Entrevistas com Alexandre, 1/12/2004, e Carlos, $24 / 11 / 2004$. Carlos foi militante do grupo Somos e também esteve presente nas primeiras articulações do movimento homossexual em resposta à Aids. Atualmente é militante do movimento homossexual.

7 Entrevista com Maria, 13/11/2004. Ela teve contato com o movimento feminista e participou de grupos lésbicos no final dos anos de 1980 e início da década seguinte. É atualmente militante do movimento homossexual.

8 Entrevista com Carlos, 24/11/2004.

9 Entrevista com Carlos, 24/11/2004 e Antônio, 19/11/2004. Antônio é ex-militante do movimento homossexual, teve contato com o grupo Lambda na década de 1980 e militou no movimento na década de 1990.

10 Entrevista com Alexandre, 1/12/2004.

11 Entrevista com Antônio, 19/11/2004.

12 Entrevista com Antônio, 19/11/2004.

13 "Art. 10 - O jornalista não pode: a) concordar com a prática de perseguição ou discriminação por motivos sociais, políticos, religiosos, raciais, de sexo e de orientação sexual" (Silva, 1993).

14 O entrevistado Antônio citou mais dois grupos Libertos, que tinha sede na Zona Norte da capital, e Eros. Segundo ele, ambos tiveram contato com o Lambda, mas não soube dizer o tempo de existência desses grupos, nem relatar especificamente quais eram suas atividades.

15 Entrevista com Antônio, 19/11/2004.

16 Ver site http://www.cpdoc.fgv.br/dhbb/verbetes_htm/4387_8.asp.

17 Entrevista com Maria, 13/11/2004.

18 Após intenso debate, optou-se pelo uso desse termo, uma vez que não estaria embutida aí a idéia da homossexualidade como algo voluntário. "Orientação sexual" comportaria um terreno neutro, sem implicações de ordem médica ou moral (Silva, 1993). Como afirma Facchini, esta "solução de con- 
senso" relaciona-se a uma ação mais pragmática do movimento, menos preocupada com a transformação sociocultural e mais voltada "para garantia dos direitos civis e contra a discriminação e violência dirigida aos homossexuais" (2002, p. 80).

19 Entrevista com Antônio, 19/11/2004.

20 Glusp (Gays e Lésbicas da USP), Etcétera e Tal, GH-PT (Grupo de Homossexuais do PT) e Urânia (Facchini, 2002, p. 89)

21 Entrevista com Antônio, 19/11/2004.

22 Projeto de Lei no.1.151/1995. "Projeto permite adoção de criança por gays solteiros", em Folha de São Paulo, 24/6/1995.

23 Entrevista com Antônio, 19/11/2004.

24 A partir do encontro de 1995, os eventos nacionais e internacionais do movimento homossexual passaram a contar com recursos do Ministério da Saúde (Facchini, 2002).

25 "Gays pedem voto contra o preconceito", em Folha de São Paulo, 15/07/1996.

26 Para mais detalhes dos conflitos em torno da organização desses eventos, consultar Facchini (2002).

27 A Parada teve o lema: "Gays, Lésbicas e Travestis: em todos os lugares, em todas as profissões" (Revista Oficial da Parada do Orgulbo GLBT de SP, $1^{\mathrm{a}}$ edição).

28 A partir de 2000 foi incluído à sigla o termo "bissexuais (Revista Oficial da Parada do Orgulbo GLBT de SP, $1^{\text {a }}$ edição).

29 "Parada Gay reúne 1,5 milhão e bate recorde", em Folha de São Paulo, 14/6/2004.

30 Ver site http://mixbrasil.uol.com.br/extra!/carecas.ht.

31 Ver site http://www.estoufelizassim.hpg.ig.com.br/ cronologia3.html.

32 "Bar em São Paulo discrimina lésbicas", em Central de Notícias Mix Brasil, 11/4/2002.

33 "Beijaço lota área em shopping de SP", em Folha de São Paulo, 4/8/2003.

34 Ver site http://www.al.sp.gov.br/index4.htm.

35 Lei Estadual n. 10.948/2001.

36 "Defensoria Homossexual começa a funcionar em São Paulo", em Central de Notícias Mix Brasil, 29/10/2001. "Orientação Normativa Iprem n. ${ }^{\circ}$ 06, de 13 de novembro de 2002", no site http://portal.prefeitura.sp.gov.br/empresas_autarquias/iprem/balan$\mathrm{co} / 0016$.
37 Gays, Lésbicas e Simpatizantes.

38 Para maiores detalhes sobre a idéia de pink money, ver Santos (2006).

39 Entrevista com Antônio, 19/11/2004.

40 Entrevista com Carlos, 24/11/2004.

41 "Aids ajuda no surgimento de grupos gays", em FSP, 14/6/1995.

42 "Orientação Normativa Iprem n. ${ }^{\circ}$ 06, de 13 de novembro de 2002", no site http://portal.prefeitura.sp.gov.br/empresas_autarquias/iprem/balan$\mathrm{co} / 0016$.

43 "Projeto ensina professores a lidar com diversidade sexual”, em Central de Notícias Mix Brasil, 22/5/2002.

44 Cidadania, Orgulho, Respeito, Solidariedade e Amor: Grupo de Conscientização e emancipação das minorias sexuais.

45 "Beto de Jesus vai representar comunidade gay no Orçamento Participativo de SP", em Central de Notícias Mix Brasil, 14/8/2002.

46 "Prefeitura fecha ponto de pegação em SP", em Central de Notícias Mix Brasil, 17/5/2002.

47 "Autorama reabre em São Paulo sob condições", em Central de Notícias Mix Brasil, 5/6/2002.

48 "Jardim dos gays", em Folha de São Paulo, 10/7/2002, e "Prefeitura de São Paulo quer transformar Autorama em jardim gay", em Central de Notícias Mix Brasil, 12/7/2002.

49 "Prefeitura de São Paulo pode ampliar horário de funcionamento do Ibirapuera", em Central de Notícias Mix Brasil, 22/7/2002.

50 "À prefeita de São Paulo", em Folha de São Paulo, 4/6/2003.

51 "Fiscais da genitália alheia", em Folha de São Paulo, 21/7/2002.

52 Entrevista com Carlos, 24/11/2004.

53 "Fiscais da genitália alheia", em Folba de São Paulo, 21/7/2002.

54 Entrevista com Carlos, 24/11/2004.

55 Entrevista com Maria, 13/11/2004.

\section{Bibliografia}

CARDOSO, Ruth Correa Leite. (2004) "A trajetória dos movimentos sociais", in E. Dagnino (org.), Anos 90: politica e sociedade no Brasil, São Paulo, Brasiliense. 
CARDOSO, Ruth Correa Leite. (1983) "Movimentos sociais urbanos: balanço crítico", in Bernardo Sorj e Maria Hermínia Tavares de Almeida (eds.), Sociedade e política no Brasil pós-64, São Paulo, Brasilense.

CARVAlHO, Maria do Carmo A. A. (1998), "Participação social no Brasil hoje". Polis, papers 2.

CERQUEIRA, Marcelo e MOTT, Luiz. (2002), "Interfaces da violência: Aids e homofobia", in C. Câmara \& C. M. P. Carneiro (orgs.), O outro como semelhante: direitos humanos e Aids, Brasília, Ministério da Saúde.

DAGNINO, Evelina. (2003), "Sociedade civil, participação e cidadania: de que estamos falando?". Trabalho apresentado no Colóquio Internacional "Políticas de Ciudadanía y Sociedad Civil en Tiempos de Globalización", Caracas.

(2004), "Os movimentos sociais e a emergência de uma nova noção de cidadania", in (org.), Anos 90: politica e sociedade no Brasil, São Paulo, Brasiliense.

DOIMO, Ana Maria. (1995), A vez e a voz do popular: movimentos sociais e participação política no Brasil pós-70. Rio de Janeiro, Relume-Dumará.

DURHAM, Eunice Ribeiro. (1984), "Movimentos sociais: a construção da cidadania". Novos Estudos Cebrap, 10: 24-30.

ENGEL, Stephen M. (2001), The unfinished revolution: social movement theory and the gay and lesbian movement. Cambridge, Cambridge University Press.

EVERS, Tilman. (1984), "Identidade: a face oculta dos novos movimentos sociais". Novos Estudos Cebrap, 2 (4): 11-23.

FACCHINI, Regina. (2002), "Sopa de letrinhas?" Movimento homossexual e produção de identidades coletivas nos anos 90: um estudo a partir da cidade de São Paulo. Dissertação de mestrado, Campinas, Universidade Estadual de Campinas.

FRY, Peter. (1982), Para inglês ver: identidade e política na cultura brasileira. Rio de Janeiro, Zahar Editores.
GALVÃO, Jane. (2000), Aids no Brasil: a agenda de construção de uma epidemia. São Paulo, ABIA/Editora 34.

GAURI, Varun \& LIEBERMAN, Evan. S. (2004), "Aids and the State: the politics of government responses to the epidemic in Brazil and South Africa", pesquisado no site http://media-cyber.law.harvard.edu/blogs/ gems/politicshiv/liebermanpaper.pdf.

GOHN, Maria da Glória. (2002), Teorias dos movimentos sociais: paradigmas clássicos e contemporâneos. São Paulo, Edições Loyola.

GREEN, James N. (2000), "Mais amor e mais tesão: a construção de um movimento brasileiro de gays, lésbicas e travestis". Cadernos Pagu, 15: 271-295.

LAVAlle, A.; CASTEllo, G. \& BICHIR, R. M. (2004), "Quando novos atores saem de cena: continuidade e mudança na centralidade dos movimentos sociais". Política e Sociedade, 5: 35-53.

MACRAE, Edward. (1990), A construção da igualdade: identidade sexual e politica no Brasil da "abertura". Campinas, Editora da Unicamp.

(1992), "Homosexual identities in transitional Brazilian politics", in S. Alvarez e A. Escobar (orgs.), The making of social movements in Latin America: identity, strategy and democracy, Colorado, Westview Press.

(1997), "Movimentos sociais e os direitos de cidadania dos homossexuais", in Ângela M. C. Araújo (org.), Trabalbo, cultura e cidadania: um balanço da história social brasileira, São Paulo, Scritta.

MESSEDER PEREIRA, Carlos A. (2004), "O impacto da aids, a afirmação da 'cultura gay' e a emergência do debate em torno do 'masculino' - fim da homossexualidade?", in L. F. Rios, V. Almeida, R. Parker, C. Pimenta e V. Terto Jr. (orgs.), Homossexualidade: produção cultural, cidadania e saúde, Rio de Janeiro, ABIA.

MINISTÉRIO DA SAÚDE. (1998), "Aids no Brasil: um esforço conjunto governo-sociedade". Brasília, Coordenação Nacional de DST e 
Aids/Ministério da Saúde.

NUSSBAUMER, Gisele Marchiori. (2001), "Cultura e identidade gay: a diferença do múltiplo". Trabalho apresentado no XXIV Congresso Brasileiro de Ciências da Comunicação da Intercom - Sociedade Brasileira de Estudos Interdisciplinares da Comunicação, realizado em Campo Grande, MS.

OTTMANN, Götz. (1995), "Movimentos sociais urbanos e democracia no Brasil: uma abordagem cognitiva". Novos Estudos Cebrap, 41: 186-207.

PARKER, Richard. (1994), A construção da solidariedade: Aids, sexualidade e política no Brasil. Rio de Janeiro, Relume-Dumará/ ABIA/IMS/UERJ.

PONTES, Heloísa A. (1986), Do palco aos bastidores: o SOS Mulber (SP) e as práticas femininas contemporâneas. Dissertação de mestrado, Campinas, Universidade Estadual de Campinas.

SADER, Eder. (1988), Quando novos personagens entram em cena. Rio de Janeiro, Paz e Terra.

SANTOS, Gustavo Gomes da Costa. (2006), Estado, projetos políticos e trajetórias individuais: um estudo com as lideranças bomossexuais na cidade de São Paulo. Dissertação de mestrado, Campinas, Universidade Estadual de Campinas.

SCHERER-WARREN, Ilse. (1994), "Organizações não-governamentais na América Latina: seu papel na construção civil". São Paulo em Perspectiva, 8 (3): 6-14.

SILVA, Cristina Luci C. da. (1993), Triângulo rosa: a busca pela cidadania dos "bomossexuais". Dissertação de mestrado, Rio de Janeiro, Universidade Federal do Rio de Janeiro (datilo.).

SILVA, Lindinalva Laurindo da. (1986), Aids e bomossexualidade em São Paulo. Dissertação de mestrado, São Paulo, Pontifícia Universidade Católica de São Paulo (datilo.).

TARROW, Sidney. (2004), El poder en movimiento: los movimientos sociales, la acción colectiva y la política. 2 ed. Madrid, Alianza Editorial.
TEIXEIRA, Ana Cláudia C. (2002), "A atuação das organizações não-governamentais: entre o Estado e o conjunto da sociedade", in E. Dagnino (org.), Sociedade civil e espaços públicos no Brasil, São Paulo, Paz e Terra.

(2003), Identidades em construção: as organizações não-governamentais no processo brasileiro de redemocratização. São Paulo, Annablume/Fapesp/Instituto Polis.

TEIXEIRA, Paulo R. (1997), "Políticas públicas em Aids", in R. Parker (org.), Politicas, instituições e Aids: enfrentando a epidemia no Brasil, Rio de Janeiro, Jorge Zahar Editor/ABIA

TERTO JR., Veriano. (1996), "Homossexuais soropositivos e soropositivos homossexuais: questões da homossexualidade masculina em tempos de Aids", in R. Parker e R. M. Barbosa (orgs.), Sexualidades brasileiras, Rio de Janeiro, Relume-Dumará/ABIA/ IMS/UERJ.

TREVISAN, João S. (1986), Devassos no paraíso. $1^{\mathrm{a}}$ edição. São Paulo, Max Limonad.

(2000), Devassos no paraíso: a bomossexualidade no Brasil, da colônia à atualidade. 3 ed. Rio de Janeiro, Record.

VAID, Urvashi. (1995), Virtual equality: the mainstreaming of gay \& lesbian liberation. Nova York, Anchor Books. 
MOBILIZAÇÕES HOMOSSEXUAIS E ESTADO NO BRASIL: SÃO PAULO (1978-2004)

Gustavo Gomes da Costa Santos

Palavras-Chave: Movimentos SOciais; Movimento homossexual; Aids; Homossexualidade; Relação sociedade-Estado.

Este texto analisa as mobilizações do movimento homossexual na cidade de São Paulo, no período de 1978 a 2004. O objetivo é entender de que forma a relação desse movimento com o Estado dificulta ou facilita a mobilização em torno da homossexualidade, principalmente no atual contexto da epidemia da Aids.
HOMOSEXUAL MOBILIZATION AND STATE IN BRAZIL: SÃO PAULO (1978-2004)

Gustavo Gomes da Costa Santos

Keywords: Social movements; Homosexual movements; AIDS; Homosexuality; Society-State relation.

This paper analyses the mobilizations of the homosexual movement in the city of São Paulo in the period between 1978 and 2004. The objective is to understand how the relation of this movement with the State has eased or hardened the mobilization around homosexuality, especially in the current context of the AIDS epidemic.
MOBILISATIONS HOMOSEXUELLES ET ÉTAT AU BRÉSIL : SÃO PAULO (1978-2004)

Gustavo Gomes da Costa Santos

Mots-clés: Mouvements sociaux; Mouvement homosexuel; SIDA; Homosexualité; Rapport société-État.

Ce texte analyse les mobilisations du mouvement homosexuel dans la ville São Paulo, au cours des années 1978 à 2004. L'objectif est de comprendre de quelle façon le rapport de ce mouvement avec l'État difficulte ou facilite la mobilisation autour de l'homosexualité, principalement dans le contexte actuel de l'épidémie du SIDA. 